\title{
A Systematic Review of Canadian EngineERING EDUCATION RESEARCH 2004-2017
}

\author{
Robert Brennan, Ron Hugo, Kim Johnston, Nancy Nelson, Robyn Paul, Monique Sullivan \\ Schulich School of Engineering, University of Calgary \\ rbrennan@ucalgary.ca
}

\begin{abstract}
This paper provides a systematic review of engineering education research papers from the $C 2 E 2 / C D E N / C E E A-A C E G-A C E G$ series of conferences from 2004 to the present. The purpose of the review is to track the evolution of engineering education across the "engineering practice" and "engineering research/theory" spectrum. The analysis is based on the National Science Foundation-funded RREE committee's proposed four levels of rigor in inquiry about teaching and learning. The results of the review show that although there is a trend towards an increasing proportion of theory-oriented papers, practice-oriented papers still dominate.
\end{abstract}

Keywords: Discipline-based Education Research: Practice-oriented Research: Theory-oriented Research

\section{INTRODUCTION}

Interest in engineering education research has steadily grown in Canada since the early 2000's as evidenced by the C2E2 (Canadian Conference on Engineering Education), CDEN (Canadian Design Engineering Network), and CEEA-ACEG (Canadian Engineering Education Association) series of conferences. The authors' involvement dates to the 2001 Canadian Conference on Engineering Education in Victoria, and has spanned the entire series of CDEN and CEEA-ACEG conferences. Over this time, we have seen a steady progression in engineering education research from predominantly practice oriented papers to an increasing number of research/theory oriented papers. As Felder and Hadgraft [5] observe, this is not an uncommon trend: i.e., engineering education research has evolved from "research that mainly consists of using student satisfaction surveys and instructors' impressions to assess the effectiveness of teaching, methods, courses, and curricula ... to more 'rigorous' [research] using methods and philosophies drawn from the social sciences".

The C2E2/CDEN/CEEA-ACEG series of conferences have brought together faculty members from across Canada who share an interest in undergraduate engineering education. Although many papers are motivated by individual faculty members' personal experiences and interests as educators, an increasing number of papers are driven by the need for programlevel change. For example, many recent studies report on addressing accreditation requirements and/or institutional curriculum review requirements. However, increasingly there is a recognition that individual, ad hoc approaches are insufficient to support these called-for changes. As Watson [9] notes, "action, uninformed by research, has led to mistakes, wasted resources, and inadequate foundations for future efforts ... it is time to focus energy on what we need to change in engineering education and how much the research can inform the transitions we need."

Given this need for discipline-based educational research that can inform change, it is not surprising to see the trend towards more "rigorous" research noted by Felder and Hadgraft. However, most engineering faculty are not trained in discipline-based educational research practices $[7,8]$. For example, as Borrego [1] notes, engineering faculty encounter numerous difficulties designing studies such as "framing research questions with broad appeal, grounding research in a theoretical framework, fully considering operationalization and measurement of constructs, appreciating qualitative or mixed-methods approaches, and pursuing interdisciplinary collaboration."

These challenges certainly create barriers for engineering faculty who see the need to move their practice-oriented research to more "rigorous," theorybased research; especially, given that engineering faculty are balancing their engineering education research with their engineering discipline-based research. However, before discounting the value of practice-oriented research we should ask, is there no longer a place for this type of research at engineering education conferences such as the C2E2/CDEN/CEEA-ACEG series? Our view is that this is not the case: there is value in both types of papers, and in fact, the use of the word "rigorous" is misleading. As Felder and Hadgraft note "...the current case for rigorous research rests on several hypotheses that have been 
accepted with neither critical examination nor plausible theoretical or empirical support." [5]

In this paper, we provide a systematic review of engineering education research papers from the C2E2/CDEN/CEEA-ACEG series of conferences from 2004 to the present. The source used for the review is the CEEA-ACEG/ACEG Archives hosted by Queen's University [3]. The purpose of the review is to track the evolution of engineering education across the "engineering practice" and "engineering research/theory" spectrum. More specifically, we analyze the papers based on Streveler and Smith's [6] description of "rigorous research in engineering education," and use the National Science Foundation-funded RREE (Rigorous Research in Engineering Education) committee's proposed four levels of rigor in inquiry about teaching and learning as a basis for the systematic review [8]:

Level 1 - Excellent teaching: Good content and methods but no formal inquiry intended to improve teaching quality.

Level 2 - Scholarly teaching: Classroom assessment but no testable and replicable scholarship.

Level 3 - Scholarship of teaching: Inquiries into teaching and learning and presentation of results in a public forum where they can be critiqued, evaluated, and built on by others.

Level 4 - Rigorous research: Inquiries that meet the Level 3 standards and three more criteria: (1) Begins with a research question (focuses on why and how learning occurs) rather than an assessment question (what and how much is learned); (2) ties the research question to learning, pedagogical, or social theory and interprets the results in light of the theory; and (3) pays careful attention to the study design and methods, adding validity, reliability, and impact to the findings.

It is hoped that the results of this review will provide the Canadian engineering education community with insights into the trends in Canadian engineering education research. Despite the increased focus and weight that is placed on engineering education research that meets RREE's "Level 4," the authors agree with Felder and Hadgraft's view that it is troublesome characterizing only this level as "rigorous research." More specifically, the RREE's definition has the potential to discount the value of applied research in engineering education, even when it meets traditional standards of quality, clarity, and potential impact. As the C2E2/CDEN/CEEA-ACEG series of conferences have demonstrated, it is through a combination of theory and practice oriented research that we can build the foundation for student success in engineering.
The paper is organized as follows. We begin with a description of the methodology used to conduct the systematic review in Section 2. This is followed by a presentation and a discussion of the results in Section 3, and the conclusions in Section 4.

\section{METHODOLOGY}

The general purpose of a systematic review is to extract "trends, patterns, relationships, and the overall picture from ... collected studies" [2]. In this case, our purpose is to report on trends in the C2E2/CDEN/CEEAACEG series of conference papers along the "practice/theory" spectrum, using the CEEAACEG/ACEG Archives hosted by Queen's University [3] as our source. As noted previously, we use the RREE committee's proposed four levels of rigor for inquiry about teaching and learning [8] as a starting point for our classification for the systematic review.

We first classify papers as "Practice" or "Theory" and used Felder and Hadgraft's [5] definitions of "practitioner" and "theoretician" to guide this classification: i.e., practice papers focus primarily on "improving teaching structures or methods," while theory papers focus primarily on "understanding the learning process at a fundamental level." We recognize that there may be some overlap in this classification given that some papers have aspects of both "practice" and "theory;" however, to make this classification, we identified the primary focus of the paper.

Next, we looked to see if a formal inquiry was performed. Ideally, this would be a full study with a research question and a method that typically would have research ethics board approval. However, we also included "inquiry-based" papers that presented survey and/or interview results with relatively informal descriptions of the methodology. For "practice" papers, the formal studies typically focus on questions around "what and how much is learned" (e.g., classroom assessments). For "theory" papers, the formal studies typically focus on questions around "why and how learning occurs" (e.g., studies on how students interact with online/flipped learning approaches).

If the answer to "formal inquiry?" was "no", we classified the paper as "Level 1", with a "practice" or "theory" sub-classification. For example, we viewed many of the graduate attribute / continual improvement papers without a formal inquiry as Level 1 - Theory. Our reasoning in this case is that, although the GA/CI process relies on classroom assessment, it is primarily about understanding the learning process at a fundamental level given its focus on continual improvement.

If the answer to "formal inquiry?" is "yes," we then looked at the nature of the inquiry in more detail. More specifically, we looked to see if there was a clear 
methodology and structure to the study that would make it "testable and replicable." Ideally, there should be a test of the validity of the results for these papers (e.g., tests for statistical significance such as t-test, ANOVA); however, we gave papers some latitude if they lacked detailed statistical analysis, but had a clear research question, methodology, and results. If the answer to this question was "no", we classified the paper as Level 2 (with the same "practice" and "theory" sub-classifications). If the answer was "yes", we would classify the paper as Type 3 for "practice" and Type 4 for "theory." A graphical representation of this classification process is shown in Figure 1.

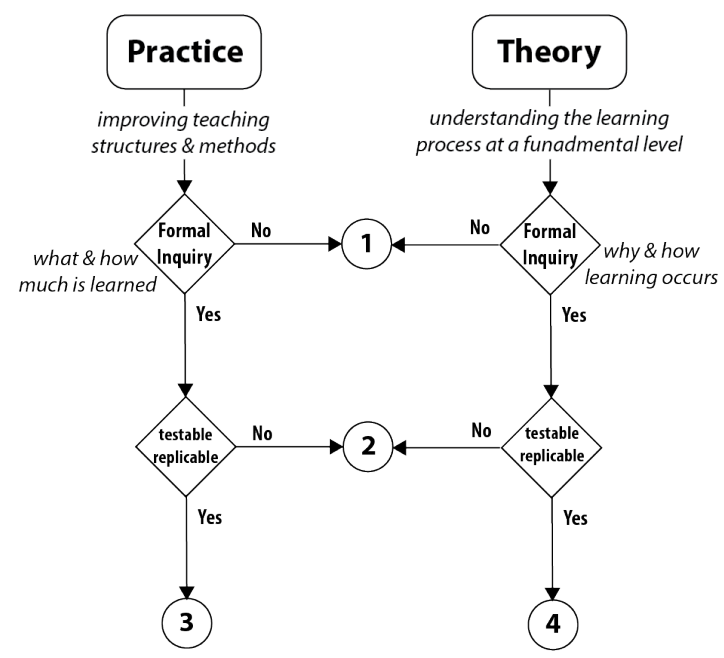

Fig. 1. The classification process.

One of the consequences of this interpretation of the RREE committee's proposed four levels of rigor for inquiry about teaching and learning is that both practiceoriented and theory-oriented papers can be classified as "rigorous." More specifically, Level 3 and Level 4 are really at the same level in terms of rigor - they only differ in their focus: the first on "improving teaching structures or methods" and the second on "understanding the learning process at a fundamental level."

\section{RESULTS AND DISCUSSION}

A total of 1,251 papers were classified, spanning the 2004-2017 series of conferences. Most of these papers were engineering education papers; however, the earlier conferences (2004-2008) also included many design engineering papers, which were excluded from this study. The comparison of "practice" oriented vs. "theory" oriented papers is shown in Figure 2 (on page 4): the number of papers and the proportion of papers in each category are shown by bar plots and line plots respectively.

As can be seen in this figure, the general trend described previously is evident. Although most papers fall into the "practice" category, the proportion of "theory" papers have increased.

Figures 3 and 4 (on page 5) provide more insights into the nature of the practice-oriented and theory-oriented papers, respectively. In these figures, the classification described in Figure 1 is used.

- Experience Papers: Papers at RREE "Level 1" are represented as "experience" papers to reflect that the authors are reporting on their experiences, without references to formal studies. These papers report on good content and methods, but do not involve formal inquiry.

- Inquiry Papers: Papers at RREE "Level 2" are represented as "inquiry" papers. These papers involve a formal inquiry/study.

- Testable Papers: Papers at RREE "Level 3" and "Level 4" are represented as "testable" papers. In this case, the inquiries reported in these papers appear to be testable and repeatable. As noted previously, we consider levels 3 and 4 to be equivalent in terms of the level of rigor: they only differ in their focus on practice or theory respectively.

As noted previously, we have modified the RREE classification somewhat to allow for practice papers (that report on improving teaching structures and methods) and theory papers (that report on understanding the learning process at a fundamental level) at levels 1 and 2 .

As can be seen in Figure 3, there has been a trend towards an increasing proportion of practice-oriented papers that are inquiry-based (i.e., have a research question that is investigated through a formal study). As well, the proportion of testable/repeatable studies (Level 3 ) has also increased. This can be seen comparing the papers from 2012-2017 where, in 2015, the number of Level 3 (testable) papers starts to exceed the number of Level 2 (inquiry) papers.

There still is a preponderance of "experience" (RREE "Level 1") practice oriented papers: for example, in 2017, $52 \%$ of the practice-oriented papers do not include an inquiry. This is not surprising given that practice-oriented papers focus on improving teaching structures and methods, and often involve reporting on faculty experience with an intervention (e.g., re-design of a laboratory). However, Figure 3 indicates that more and more faculty are seeing the value in conducting a study to report on the efficacy of their interventions.

The results for the theory-based papers (Figure 4) show a similar trend as the practice-oriented papers (i.e., an increase in the number of papers including inquiries); however, in this case the proportion of papers that include formal inquiries is much higher. Of note, in 2015, the number of theory-based papers that include a formal inquiry exceed those that do not $(60 \%$ of the theory-based 


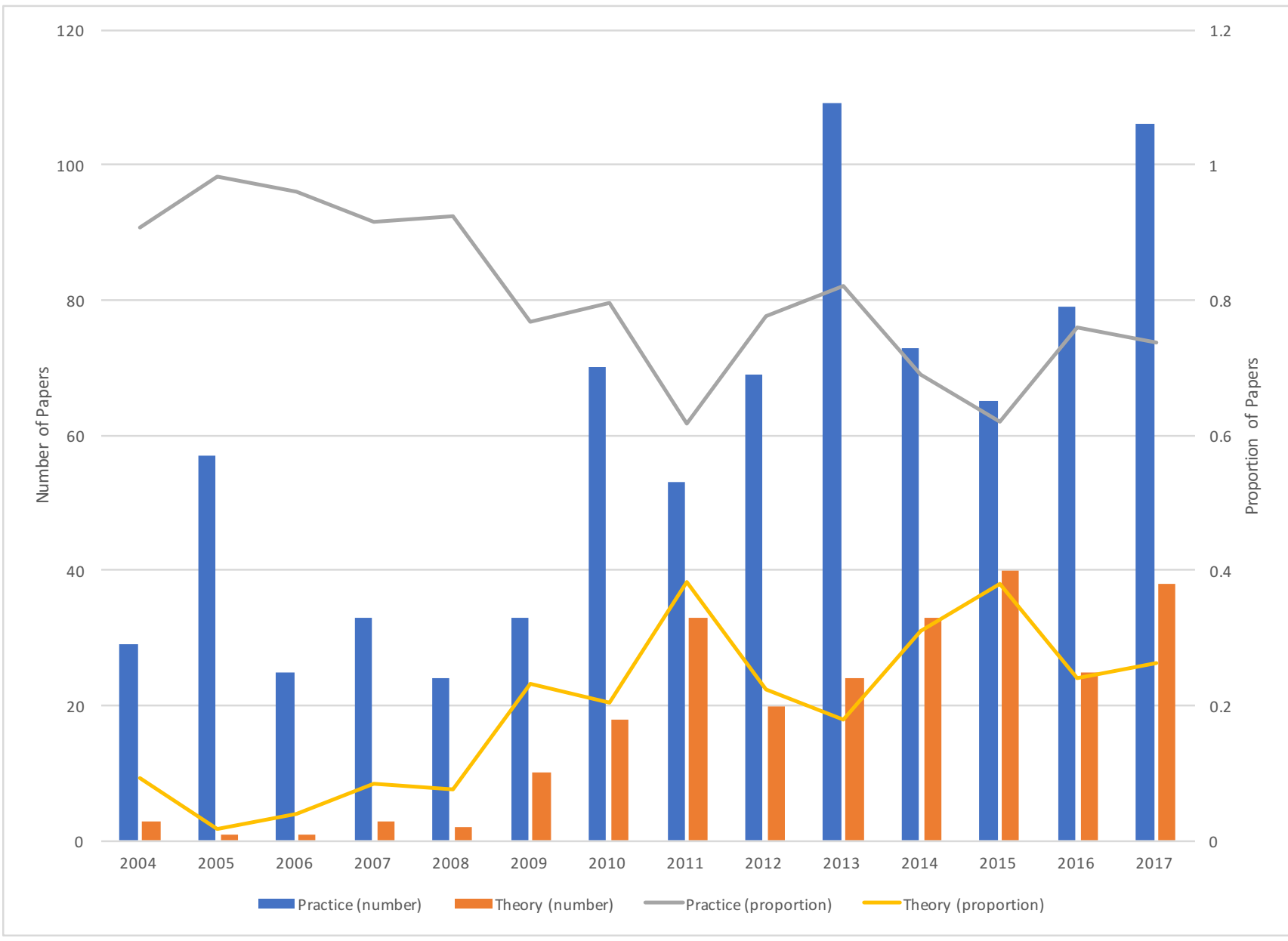

Fig. 2. CEEA-ACEG/ACEG archives papers classified according to general focus: practice $v$. theory.

papers are "inquiry" or "testable" papers). As well, starting in 2010 , most of the inquiry-based papers in this category are testable/replicable (i.e., RREE "Level 4").

Given that these papers focus on understanding the learning process at a fundamental level, it is not surprising to see a focus on formal inquiries that address a research question.

\section{CONCLUSIONS}

As stated previously, our hope for this study was to provide the Canadian engineering education community with insights into the trends in Canadian engineering education research. The approach used to classify the papers from the $\mathrm{C} 2 \mathrm{E} 2 / \mathrm{CDEN} / \mathrm{CEEA}-\mathrm{ACEG}$ series of conferences was based on a widely agreed-upon classification for levels of rigor in engineering education research (the RREE's proposed four levels of rigor in inquiry about teaching and learning) with modification to account for practice-oriented research that included inquiry. However, based on our experience with the review, there is a level of subjectivity to the classification of papers using this system which may result in some limitations to the conclusions drawn from the survey. Despite this limitation, we feel that the review does provide a useful picture of the evolution of engineering education research in Canada.

In particular, the results of the review show that there is a trend towards more "rigorous" papers (i.e., RREE Levels 2-4). Although the number of theory-based papers is increasing, they typically account for less than $30 \%$ of the papers at recent conferences: clearly, there is still considerable interest in the CEEA-ACEG community in practice-oriented papers. The more telling result is that we see a trend toward increases in the number of inquirybased papers in both the practice and theory areas. In other words, engineering education researchers are identifying research to address why and how learning 
occurs (theory) as well as studies to address what and how much is learned (practice).

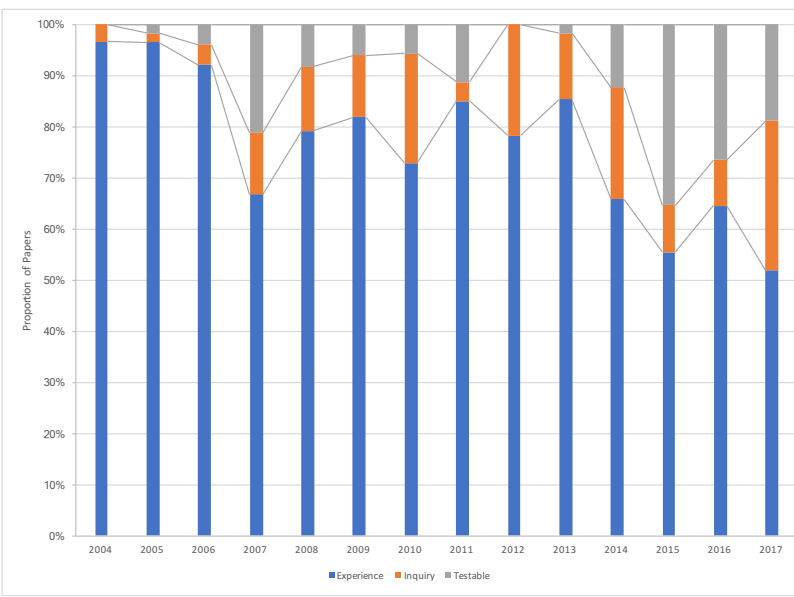

Fig. 3. CEEA-ACEG/ACEG archives "practice" papers classified according to level of rigor.

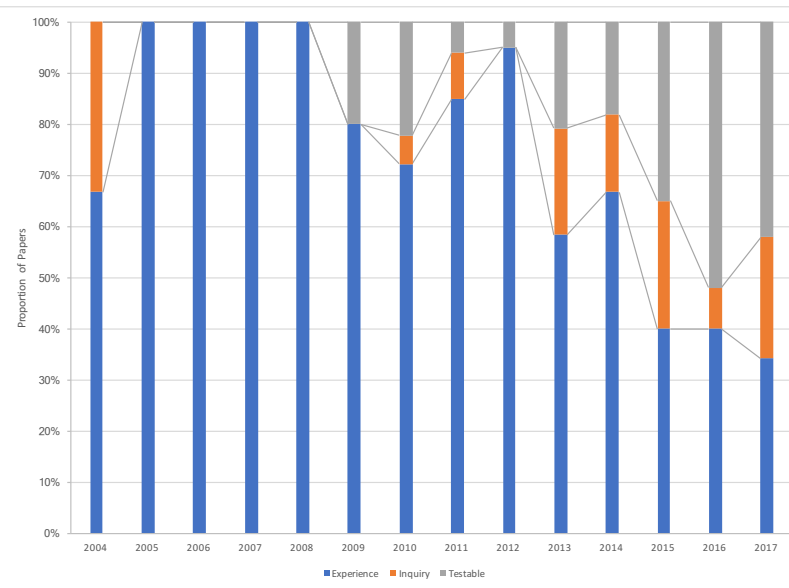

Fig. 4. CEEA-ACEG/ACEG archives "theory" papers classified according to level of rigor.

As Felder and Hadgraft [5] note, "... the engineering education community has begun to split into two divergent and sometimes antagonistic groups: the theoreticians ... and the practitioners." Based on what we have seen in the C2E2/CDEN/CEEA-ACEG series of conferences, this does not have seem to become the case in Canada. Many significant engineering education reforms have been the result of initiatives that were not based on rigorous research: e.g., the shift towards an "engineering science" in the 1950's, the emphasis on capstone design in the 1990's [5]. We have no reason to believe that this will not continue to be the case in the future. However, it is important to also recognize that much can be gained by applying what we learn from theoretical studies on why and how learning occurs. As well, it is important to reflect back on Watson's [9] observation noted earlier in this paper concerning the need for research-informed engineering education reform. Our view is that both practice and research oriented research have a role to play in this regard. It is our hope that the Canadian engineering education community will continue to see value in both forms of engineering education research, as well as recognize that both approaches can be equally rigorous.

\section{Acknowledgements}

The authors wish to thank the Natural Sciences and Engineering Research Council, Spartan Controls, the Suncor Energy Foundation, and the Schulich School of Engineering for their generous support of this research.

\section{References}

[1] Maura Borrego, "Conceptual difficulties experienced by trained engineers learning educational research methods", Journal of Engineering Education, vol. 96, no. 2, pp. 91-102, 2007.

[2] Maura Borrego, Margaret J. Foster, and Jeffrey E. Froyd, "Systematic literature reviews in engineering education and other developing interdisciplinary fields", Journal of Engineering Education, vol. 103, no. 1, pp. 45-76, 2014.

[3] CEEA-ACEG/ACEG Archives, https://ojs.library. queensu.ca/index.php/PCEEA-ACEG/issue/archive.

[4] Kerrie A. Douglas and Senay Purzer, "Validity: Meaning and Relevancy in Assessment for Engineering Education Research", Journal of Engineering Education, vol. 104, no. 2, pp. 108-118, 2015.

[5] Richard M. Felder and Roger G. Hadgraft, "Educational practice and educational research in engineering: partners, antagonists, or ships passing in the night?", Journal of Engineering Education, vol. 102, no. 3, pp. 339-345, 2013.

[6] Ruth A. Streveler and Karl A. Smith, "Conducting rigorous research in engineering education", Journal of Engineering Education, vol. 95, no. 2, pp. 103-105, 2006.

[7] Ruth A. Streveler, Nicole P. Pitterson, and Juan Ortega Alvarez, "Learning about engineering education research: what conceptual difficulties still exist for a new generation of scholars?", in the Proceedings of the 2015 IEEE Frontiers in Education Conference (FIE), 2015.

[8] Ruth A. Streveler, Maura Borrego, and Karl A. Smith, "Moving from the 'scholarship of teaching and learning' to 'educational research': an example from engineering", in D.R. Robertson (Ed.), To Improve the Academy, vol. 25, pp. 139-149, 2007.

[9] Karan Watson, "Change in engineering education: Where does research fit?", Journal of Engineering Education, vol. 98, no. 1, pp. 3-4, 2009. 